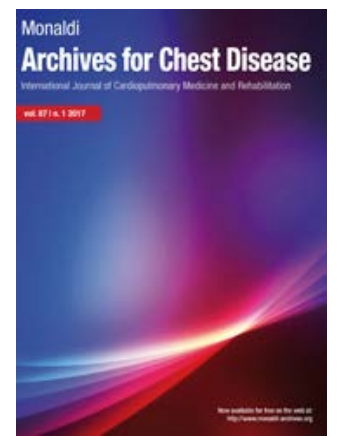

Monaldi Archives for Chest Disease

Publisher's Disclaimer. E-publishing ahead of print is increasingly important for the rapid dissemination of science. The Monaldi Archives for Chest Disease is, therefore, Epublishing PDF files of an early version of manuscripts that undergone a regular peer review and have been accepted for publication, but have not been through the copyediting, typesetting, pagination and proofreading processes, which may lead to differences between this version and the final one.

The final version of the manuscript will then appear on a regular issue of the journal. E-publishing of this PDF file has been approved by the authors.

Monaldi Arch Chest Dis 2021 [Online ahead of print]

To cite this Article:

Khalfallah I, Hajjej S, Ferchichi M, et al. Giant pulmonary hydatid cyst in children. Monaldi Arch Chest Dis doi: 10.4081/monaldi.2021.1770

(C) the Author(s), 2021

Licensee PAGEPress, Italy 


\title{
Giant pulmonary hydatid cyst in children
}

\author{
Ikbel Khalfallah ${ }^{1,2}$, Sabri Hajjej ${ }^{1,2}$, Meriem Ferchichi ${ }^{1,2}$, Abir Boussetta ${ }^{2,3}$, \\ Meriam Affes $^{2,3}$, Sabrine Louhaichi ${ }^{1,2}$, Besma Hamdi, ${ }^{1,2}$, Jamel Ammar ${ }^{1,2}$, \\ Agnès Hamzaoui ${ }^{1,2}$
}

1- Pulmonology B Department, Abderrahmen Mami Hospital, Ariana

2- Faculty of Medicine, El Manar University, Tunis

3- Pediatric Department, Charles Nicolle hospital, Tunis

4- Radiology Department, Abderrahmen Mami Hospital, Ariana, Tunisia

Corresponding author: Sabri Hajjej: hajej.hajej@hotmail.com

Conflict of interest: The authors declare that they have no competing interests, and all authors confirm accuracy.

Availability of data and materials: The datasets used and/or analyzed during the current study are available from the corresponding author on reasonable request.

Ethics approval and consent to participate: Due to the retrospective nature of the study, the IRB approval was not required, and all the data are de-identified.

Patient consent for publication: Not applicable.

Informed consent: The manuscript does not contain any individual person's data in any form.

\begin{abstract}
Hydatid disease is still endemic in Tunisia. It is mostly seen in young people less than 40 years and children are affected in one third of cases. The lungs are the predominant location in children. Our study aims to define the particularities of children PHC's (pulmonary hydatic cyst) management, the characteristics of giant cyst and to study predictive factors of complications. We included retrospectively 105 children with PHC followed between 1999 and 2019. Patients were aged less than 16 years with surgically confirmed diagnosis of PHC. Two groups of cysts were defined: giant cysts which were $10 \mathrm{~cm}$ across or more, and no giant cysts.The sex-ratio was 1,38 with a mean age of $10.5 \pm 3$ years. The symptomatology was dominated by cough (59\%), thoracic pain (51\%) and hemoptysis (46\%). Giant cysts were observed in $24(22.9 \%)$ patients. Dyspnea $(29 \%$ vs $5 \% \mathrm{p}<0.001)$ and thoracic pain $(88 \%$ vs
\end{abstract}


$.41 \% \mathrm{p}<0.001)$ were significantly more frequently reported in giant cysts. Eighty-six patients had a single cyst (83\%) and 19 had multiple cysts (17\%). Giant cysts accounted for $22,9 \%$ (24 cases). Thoracic ultrasonography was diagnostic in $77.4 \%$. The thoracic CT scan was performed in 27 children with inaccessible cysts in thoracic ultrasonography or in diagnostic doubt.Patients were all treated surgically. Surgical procedures consisted of cystectomy (59\%), pericystectomy (18\%) and pulmonary resection when parenchyma was destroyed $(23 \%)$. Parenchymal resection was more often performed in complicated cysts $(27 \%$ vs $20 \% p>0.05)$ and in giant cysts $(41 \%$ vs $18 \% \mathrm{p}<0.05)$. A two-stage thoracotomy was performed in the 4 patients with bilateral cysts. Thirteen patients presented immediate post-operative complications which occurred more frequently in complicated and giant cysts. Hospital stay was longer in complicated cysts $(16 \pm 9$ days vs $7 \pm 3$ days; $p<0.001)$ and in giant cysts $(14 \pm 9$ days vs $11 \pm 8$ days; $p>0.05$ ). In endemic regions, the diagnosis of PHC in children should be based on the combination of thoracic radiography and ultrasonography which are effective, not costly, safe and accessible. Complicated and giant PHC cause lung damage leading to extensive parenchymal resection. They are more associated with post-operative complications prolonging hospital stay and increasing expenses.

Key words: Pulmonary hydatic cyst, children, giant cyst

\section{Introduction}

Hydatid disease is still endemic in Tunisia and in many other countries in Mediterranean area, South America, New Zealand and Middle East (1-3). It is an anthropozoonosis where humans are end-stage intermediate hosts and dogs are definitive hosts. Echinococcus granulosis which is the most frequent parasite responsible for this disease is transmitted to humans via the ingestion of vegetables contaminated by the dog faeces or via direct contact with dogs (3-5). Hydatid disease is mostly seen in young people less than 40 years and children are affected in one third of cases (6). The lungs are the predominant location in children because of their higher elasticity (7). Thus, PHC (pulmonary hydatic cyst) increase more in size and giant cyst would be more frequent. Though PHC is known to be a benign disease, its complications are sometimes life-threatening emphasizing the importance of an early diagnosis and treatment. Our study aims to define the particularities of children PHC's management, the characteristics of giant cyst and to study predictive factors of complications. 


\section{Methods}

We included retrospectively 105 children with PHC followed in our Department of Paediatric and Respiratory Diseases (Abderrahmen Mami Hospital, Ariana, Tunisia) between 1999 and 2019. Patients were aged less than 16 years and with surgically confirmed diagnosis of PHC. Collected data were age, sex, origin, contact with sheep and dogs, presenting symptoms, imaging findings, diagnostic tools, cyst complications before treatment (infection, hemoptysis cysto-bronchial fistula, pneumothorax or an allergic episode), medical and surgical treatment, hospital stay, duration operative procedures and immediate post-operative complications (air leakage, pneumonia, pleural effusion, wound infection) and long-term complications (recurrence, residual cavity).

Patients were all treated surgically. In the most cases, the surgical treatment was a procedure involving cystotomy, removal of the cystic membrane, and capitonnage. Contrary to excision, these steps generally involve evacuating the cyst and then suturing to obliterate the cavity and close its edges. Any bronchial fistula in the cavity wall were closed with absorbable sutures. Once this was done, the cavity was obliterated. The rest of patients underwent decortication, and others were treated with wedge resection or lobectomy.

After surgery, all patients with complicated hydatid cysts or multiple hydatid cysts, or both, were placed on anthelmintic therapy (albendazole $10 \mathrm{mg} / \mathrm{kg}$ /day) for at least 3 months. Patients with uncomplicated or single cysts received no antiparasitic medication after their operation.

Two groups of cysts were defined: giant cysts which were $10 \mathrm{~cm}$ across or more, and no giant cysts. The data were recorded and analyzed using SPSS software version 24.0. For the descriptive study, the different variables were analyzed with calculation of simple frequencies and relative frequencies (percentages) for the qualitative variables as well as calculation of averages and standard deviations for the quantitative variables. The analytical and comparative study were studied and significant differences were identified. The standard $\mathrm{p}$ threshold of 0.05 was considered significant for all analyses. Chi-2 test was used to compare qualitative variables and Student $\mathrm{T}$ test to compare quantitative variables to binary qualitative variables.

\section{Results}

\section{Sex and age}

The group of patients consisted of 61 boys and 44 girls. The age ranged between 3 and 16 years with a mean age of $10.5 \pm 3$ years. Only $9,5 \%$ were aged less than 6 years. 


\section{Context of hydatid exposure}

All our patients came from rural areas (North West and centre of Tunisia) and 80\% were in contact with sheep and dogs.

\section{Presenting symptoms}

All the children were symptomatic. The presenting symptoms included cough (59\%), thoracic pain (51\%), hemoptysis (46\%), fever (39\%) and dyspnea (10\%). Hydatid vomica was described in $13 \%$ of children.

Giant cysts were observed in $24(22.9 \%)$ patients. Dyspnea $(29 \%$ vs $5 \% \mathrm{p}<0.001)$ and thoracic pain $(88 \%$ vs $.41 \% \mathrm{p}<0.001)$ were significantly more frequently reported from patients with giant cysts than the other patients. No significant difference was observed for cough, vomica or fever.

\section{Imaging findings}

\section{Chest radiography}

All children had an abnormal radiography. A total of 134 cysts were found in 105 patients. Cysts were located in the right lower lobe in $28 \%$ of cases, the right middle lobe in $18 \%$, the upper right lobe in $21 \%$, the upper left lobe in $17 \%$ and the lower left lobe in $25 \%$. In giant $\mathrm{PCH}, 66 \%$ were right and $62.5 \%$ in basal lobes.

Eighty-six patients had a single cyst (83\%) and 19 had multiple cysts (17\%). Lesions were bilateral in 7 cases. Intact cysts appeared as a well-defined round opacity.

In complicated cysts, we observed excavation (40\%), water-lily sign (16\%), air-fluid level (24\%), crescent sign (5\%).

A small pleural effusion was associated in $9 \%$ of these cases.

Giant cysts accounted for 22,9\% (24 cases). Their diameter ranged between 10 and $17 \mathrm{~cm}$ with a mean diameter of $12.7 \mathrm{~cm}$. On chest radiograph, 64\% of giant cysts appeared complicated (crescent sign, water-lily sign, excavation, air fluid level) vs $43 \%$ of the other ones (Table 1).

\section{Thoracic ultrasonography}

Thoracic ultrasonography was realised in all children. It was diagnostic in $77.4 \%$ of cysts by visualising the cyst wall sign (63\%) (Figures 1 and 2), serpent sign (12\%) or daughter cyst 
sign (2.4\%). In the remaining cases, it showed pleural effusion (4.7\%), parenchymal consolidation $(2.6 \%)$ or the cyst was inaccessible $(15.3 \%)$.

\section{Bronchoscopy}

Bronchoscopy was realised in 25 patients in case of haemoptysis. It showed hydatid membranes in 14 cases. The PHC was no giant in all these cases and $71 \%$ were complicated in imaging.

\section{Other imaging examinations}

Abdominal ultrasound was done systematically in all patients and revealed liver cysts in $28 \%$ of cases.

Thoracic CT scan was performed in 27 children with multiple cysts to specify the number and location of the different cysts before surgery, in children with inaccessible cysts in thoracic ultrasonography or in diagnostic doubt (figure 4 and 5). It didn't confirm PHC in 8 cases where it shows mass in 4 cases, parenchymal condensation in 2 cases and bronchogenic cyst in 2 cases.

\section{Surgical treatment}

Patients were all treated surgically. Surgical procedures consisted of cystectomy (59\%), pericystectomy $(18 \%)$ and pulmonary resection when parenchyma was destroyed $(23 \%)$. Lung resection consisted in lobectomy in 16 cysts, segmentectomy in 4 and atypical resection in 4. No patient required pneumonectomy.

Parenchymal resection was more often performed in complicated cysts $(27 \%$ vs $20 \% \mathrm{p}>0.05)$ and in giant cysts $(41 \%$ vs $18 \% \mathrm{p}<0.05)$. Pleural decortication was necessary in one patient with ruptured cyst in the pleural cavity.

A two-stage thoracotomy was performed in the 4 patients with bilateral cysts, after an interval of at least 3 weeks.

Thirteen patients presented immediate post-operative complications: pneumonia which responded to antibiotics in 5 patients, atelectasis in 3 treated by bronchoscopic aspiration and physiotherapy, prolonged air leakage which needed prolonged drainage in 5 cases. Postoperative complications occurred more frequently in complicated and giant cysts. These complications were more frequent in case of lung resection (table 2,3).

Hospital stay was longer in complicated cysts $(16 \pm 9$ days vs $7 \pm 3$ days; $p<0.001)$ and in giant cysts ( $14 \pm 9$ days vs $11 \pm 8$ days; $p>0.05)$. 


\section{Medical treatment}

Medical treatment (Albendazole: $10 \mathrm{mg} / \mathrm{kg} /$ day) associated with surgery was indicated in disseminated cysts ( 3 patients) or when the cyst was ruptured in the pleura (1 patient).

After surgical and medical treatment, cutaneous locations were observed in a boy with an initially disseminated pulmonary hydatid disease and a cerebral cyst. The other 3 children had a favourable course with a reduction of the number and the size of the cysts.

In children who were only treated surgically, infection of residual cavity was seen in a girl operated on for intact cyst and it evolved favourably under antibiotics.

No recurrence was noted in the other patients.

\section{Discussion}

Pulmonary hydatid disease is endemic in Tunisia and in many countries all around the world (1-3) where cattle-breeding is common (8). It interests predominantly people younger than 40 years and children account for approximately one third of the population affected (6). In children, $\mathrm{PHC}$ is more common than liver cyst (64\% lung, $28 \%$ liver) contrasting with what is usually found in adults (60\% liver, 30\% lung) (9). This could be explained by a much easier growth of the cyst in children lungs because of their higher elasticity (10). Patients coming from rural regions (4) and who are in contact with sheep and dogs are more likely to develop hydatid disease as the parasite is transmitted by direct contact with dogs and less frequently by ingestion of vegetables contaminated by dog faeces. In our study, we noted a predominance of hydatid cyst in boys. This may be due to a more frequent exposure of boys to dogs.

Intact PHC is frequently asymptomatic (11) and discovered incidentally on a chest radiograph. However, intact cyst can also cause non-specific respiratory symptoms (12). In our patients, there was no incidental finding. The presenting signs of complicated cysts depend on the type of complication (13). Hydatid vomica is the clinical pathognomonic sign of a brutal rupture of the cyst in a bronchus (11). It contains cyst fluid, scolices and membrane and is described by the patient as a sudden expectoration of a saline and clear fluid. In our series, vomica was seen in $21 \%$ of complicated cysts. Other symptoms were dominated by cough, haemoptysis and fever. The irritation, erosion and compression of structures adjacent to the cyst (ie: bronchi, vessels and parenchyma) participate in the appearance of these symptoms. Rupture of PHC in the pleural cavity is usually symptomatic and complicated either by a dissemination to the pleura leading to recurrent pleural hydatidosis, or other severe 
complications such as empyema, hydropneumothorax and anaphylaxis. Fortunately, the rupture of PHC in the pleural cavity is rare $(4,14)$. The elasticity of the lungs in children compared to adults facilitates also cyst growth, enabling giant cyst development $(6,8,15)$. Furthermore, dyspnea is late in children due to uninvolved lung tissue compensation allowing normal ventilation (6). Thoracic pain is commonly associated with giant cysts due to compression of the pleura and the chest wall.

Hydatid cysts are more often located in the right lung and the lower lobes $(13,16,17)$. The lower parts of the lungs are better vascularised than the upper ones allowing a good nutrition of the parasite ending in an easier growth (18).In our study, $67 \%$ cysts were found in the right lung and 53\% in the basal lobes. In giant $\mathrm{PCH}, 66 \%$ were right and $62.5 \%$ in basal lobes. In our serie, single cysts were predominant ( $83 \%$ vs $17 \%$ ) in concordance with the literature (19) Intact cyst presents radiologically as a round or oval well-defined homogenous opacity (17) indistinguishable from other pulmonary round opacities. Nevertheless, the diagnosis should be immediately evoked in children coming from endemic regions, particularly because of the rarity of tumours in children. Complicated cysts can have different radiologic aspects depending on the complication. Crescent sign denotes the imminence of bronchial rupture and results of the entrance of air between the pericyst and the cyst (20). Water-lily sign indicates bronchial rupture. The hydatid membrane falls and floats over the hydatid fluid. These two signs are pathognomonic of complicated PHC (21). In our series, chest X ray alone permitted the diagnosis in $21 \%$ of cysts by showing one of these two characteristic signs. Other non specific radiologic appearances are associated with complicated PHC among which air-fluid level and intracavitary air. The former is formed when bronchial rupture and infection of the cyst occur. Lung abscess is the main differential diagnosis in children. When air irrupts into the cyst, excavation is formed (22). Pleural effusion can be associated with both complicated and intact PHC because it can simply result from pleural reaction to the presence of PHC and not necessarily from perforation into the pleural cavity. In the literature, pleural complications are found in $0.5 \%$ to $18.2 \%$ (23). Pleural rupture is due to compression by peripheral and subpleural cysts (23). Giant cysts appear more frequently complicated on chest radiograph as it was found in this study ( $64 \%$ of giant cysts vs $43 \%$ ). In fact, they are more prone to rupture because of their size and their consequent capacity of eroding adjacent structures.

Thoracic ultrasonography is one of the most interesting diagnostic tools in PHC in children providing an experimented radiologist. The limitations of sonography are not important in children compared to adults, since pathologic processes are generally superficial and then easier to explore (24). In addition, mineral content of bone and cartilage is low permitting a 
good visualisation of lung lesions (24). Apart from being safe and not costly, it contributes greatly to the diagnosis of peripheral cysts when radiologic image has no specificity. In our series, it was diagnostic in $77.4 \%$ of cysts; the cyst was inaccessible in only $20 \%$. One of the characteristic signs is the wall sign which corresponds to the endocystic membrane and appears as a hyperechogenic wall surrounding a fluid formation (25). The other specific signs are daughter sign visualizing small vesicles inside the main cyst, serpent sign which indicates a collapsed hydatid membrane and crescent sign(26). A round liquid formation may be seen on ultrasound but is not diagnostic.

Abdominal ultrasound should be done systematically in search of possible associated locations (22) and to guide the diagnosis of PHC. An association of pulmonary and liver cysts was demonstrated in $32 \%$ of our cases. Moreover, the presence of a hydatid liver cyst is a strong argument in favour of the hydatid origin of an inaccessible lung lesion (4).

Medical treatment is indicated as a single treatment when surgery is contraindicated in case of inoperable patients due to cardiac and/or pulmonary performance status or in association with surgery when the cyst is ruptured in the pleural cavity $(8,21)$ or in disseminated hydatid cysts to prevent postoperative recurrences(18). Medical treatment aims to reduce the number of cysts and to kill the parasite thus controlling hydatid dissemination and recurrence. However, the cyst natural evolution may lead to its total vanishing (8). This makes the medical treatment efficiency difficult to assess. Moreover, apart from being a long $(8,19)$ and uncertain treatment, anthelminthic agents could lead to severe complications such as massive hemoptysis and hepatic toxicity (19).

Surgery is the gold standard in the treatment of PHC $(7,22,27)$ and its main aim particularly in children is the total excision of the parasite and preserve the maximum of lung tissue (28). Surgery should be as conservative as possible in order to maintain a normal pulmonary function (9). In our practice, conservative surgical techniques, such as cystectomy or cystotomy and Capitonnage plus closure of of bronchopleural fistulas and Capitonnage of the residual cystic space, constituted the surgical approach of choice for intact cysts whatever the cyst size. In These simple.procedure, postoperative complications were infrequent (12\%) and no mortality was seen in our study. Although we had a parenchyma preserving approach, no recurrence was observed in our series; this was similar to other studies $(26,29,30)$. Although it is well accepted in the literature that Parenchyma-preserving surgery is considered fundamental in the surgical management of lung hydatidosis and radical surgery should be avoided even in cases of giant hydatid cyst. Sometimes segmentectomy and even lobectomy may be inevitable $(30,31)$. Indications for parenchymal resection are giant cysts occupying the 
entire lobe, multiple cysts, and an unexpandable lobe after the excision of the cyst (29). Even if the remaining lobe does not expand adequately during operation, gradual expansion in the long term would be expected while there is no air leakage from it. Secure airtight closure of bronchial openings is invaluable in attaining such excellent results (30). The lobectomy rate in pulmonary hydatid surgery is reported to range from $0.5 \%$ to $45 \%$ in the literature (31). In our study, this rate was $18 \%$ and $16 \%$ in giant cysts.

Giant and complicated cysts were associated with a higher rate of immediate post- operative complications and a longer hospital stay. In fact, in many studies, the size of the cysts was correlated with postoperative complications such as prolonged air leakage and atelectasis (19) and with hospital stay (31). Thus, giant hydatid lung cysts must be regarded as a different clinical entity because of their early occurrence, more serious symptoms, with frequent operative complications, and the need for prolonged care with higher costs.

\section{Conclusion}

In endemic regions, the diagnosis of PHC in children should be as simple as possible and should be based on the combination of thoracic radiography and ultrasonography which are effective, not costly, safe and accessible. Complicated and giant PHC cause lung damage leading to extensive parenchymal resection. They are more associated with post-operative complications prolonging hospital stay and increasing expenses. Therefore, the importance of prophylactic measures which are simple and efficient should be emphasized.

\section{Conflict of interest}

None of the authors have any conflicts of interest to disclose.

\section{References}

1. Tünger Ö. Epidemiology of cystic echinococcosis in the world. Turk Parazitolojii Derg. 2013;37:47-52.

2. Craig PS, McManus DP, Lightowlers MW, et al. Prevention and control of cystic echinococcosis. Lancet Infect Dis 2007;7:385-94.

3. Agudelo Higuita NI, Brunetti E, McCloskey C. Cystic echinococcosis. J Clin Microbiol 2016;54:518-23.

4. Ramos G, Orduña A, García-Yuste M. Hydatid cyst of the lung: diagnosis and treatment. World J Surg 2001;25:46-57.

5. Rawat S, Kumar R, Raja J, et al. Pulmonary hydatid cyst: Review of literature. J Fam Med Prim Care 2019;8:2774-8. 
6. Halezeroglu S, Celik M, Uysal A, et al. Giant hydatid cysts of the lung. J Thorac Cardiovasc Surg 1997;113:712-7.

7. Topçu S, Kurul IC, Taştepe I, et al. Surgical treatment of pulmonary hydatid cysts in children. J Thorac Cardiovasc Surg 2000;120:1097-101.

8. Sarkar M, Pathania R, Jhobta A, et al. Cystic pulmonary hydatidosis. Lung India Off Organ Indian Chest Soc 2016;33:179-91.

9. Türky1lmaz Z, Sönmez K, Karabulut R, et al. Conservative surgery for treatment of hydatid cysts in children. World J Surg 2004;28:597-601.

10. Jerray M, Benzarti M, Garrouche A, et al. Hydatid disease of the lungs. Study of 386 cases. Am Rev Respir Dis 1992;146:185-9.

11. Kervancioĝlu R, Bayram M, Elbeyli L. CT findings in pulmonary hydatid disease. Acta Radiol 1999;40:510-4.

12. Kuzucu A, Soysal O, Ozgel M, Yologlu S. Complicated hydatid cysts of the lung: clinical and therapeutic issues. Ann Thorac Surg 2004;77:1200-4.

13. Ozmen CA, Onat S. Computed tomography (CT) findings of pulmonary hydatid cysts in children and the factors related to cyst rupture. Med Sci Monit Int Med J Exp Clin Re. 2017;23:3679-86.

14. Turgut AT, Altinok T, Topçu S, Koşar U. Local complications of hydatid disease involving thoracic cavity: imaging findings. Eur J Radiol 2009;70:49-56.

15. Kanat F, Turk E, Aribas OK. Comparison of pulmonary hydatid cysts in children and adults. ANZ J Surg 2004;74:885-9.

16. Onal O, Demir OF. The relation between the location and the perforation rate of lung hydatid cysts in children. Asian J Surg 2018;41:422-6.

17. Garg MK, Sharma M, Gulati A, et al. Imaging in pulmonary hydatid cysts. World J Radiol 2016;8:581-7.

18. Amirian A, Ziaian B, Erfani A, et al. Successful management of a huge pulmonary hydatid cyst with lung-preserving surgery. Case Rep Surg 2020;2020:9526406.

19. Karaoglanoglu N, Kurkcuoglu IC, Gorguner M, et al. Giant hydatid lung cysts. Eur J Cardiothorac Surg 2001;19:914-7.

20. Polat P, Kantarci M, Alper F, et al. Hydatid disease from head to toe. Radiogr Rev Publ Radiol Soc N Am Inc 2003;23:475-94; quiz 536-7.

21. von Sinner W. Advanced medical imaging and treatment of human cystic echinococcosis. Semin Roentgenol 1997;32:276-90.

22. Yalcinkaya I, Er M, Ozbay B, Ugras S. Surgical treatment of hydatid cyst of the lung: review of 30 cases. Eur Respir J 1999;13:441-4.

23. Aribas OK, Kanat F, Gormus N, Turk E. Pleural complications of hydatid disease. J Thorac Cardiovasc Surg 2002;123:492-7.

24. Haller JO, Schneider M, Kassner EG, et al. Sonographic evaluation of the chest in infants and children. AJR Am J Roentgenol 1980;134:1019-27.

25. El Fortia M, Bendaoud M, Shaban A, et al. Mother and daughter wall sign in ultrasound identification on non complicated hydatid cysts. New criteria. J Echographie Med Par Ultrasons 1996;17:30-5.

26. Şehitoğulları A. Our results in surgical treatment of hydatid cyst of the lungs. Electron J Gen Med 2007;4:5-8. 
27. Nabi MS, Waseem T. Pulmonary hydatid disease: what is the optimal surgical strategy? Int J Surg Lond Engl 2010;8:612-6.

28. Safioleas M, Misiakos EP, Dosios T, et al. Surgical treatment for lung hydatid disease. World J Surg 1999;23:1181-5.

29. Aldahmashi M, Alassal M, Kasb I, Elrakhawy H. Conservative surgical management for pulmonary hydatid cyst: Analysis and outcome of 148 cases. Can Respir J 2016;2016:8473070.

30. Lichter I. Surgery of pulmonary hydatid cyst - the Barrett technique. Thorax 1972;27:529-34.

31. Salih OK, Topcuoğlu MS, Celik SK, et al. Surgical treatment of hydatid cysts of the lung: analysis of 405 patients. Can J Surg J Can Chir 1998;41:131-5.

Table 1. Radiological presentations of pulmonary hydatid cysts (giant vs other cysts).

\begin{tabular}{|l|c|c|c|}
\hline & Giant cysts $(\mathrm{n}=24)$ & Other cysts $(\mathrm{n}=81)$ & $\mathrm{p}$ value \\
\hline Round opacity & $34 \%$ & $66 \%$ & 0.03 \\
\hline Crescent sign & $9 \%$ & $6 \%$ & $>0.05$ \\
\hline Water-lily sign & $10 \%$ & $7 \%$ & $>0.05$ \\
\hline excavation & $17 \%$ & $16 \%$ & $>0.05$ \\
\hline Air-fluid level & $18 \%$ & $14 \%$ & $>0.05$ \\
\hline Pleural effusion & $14 \%$ & $2 \%$ & 0.01 \\
\hline
\end{tabular}




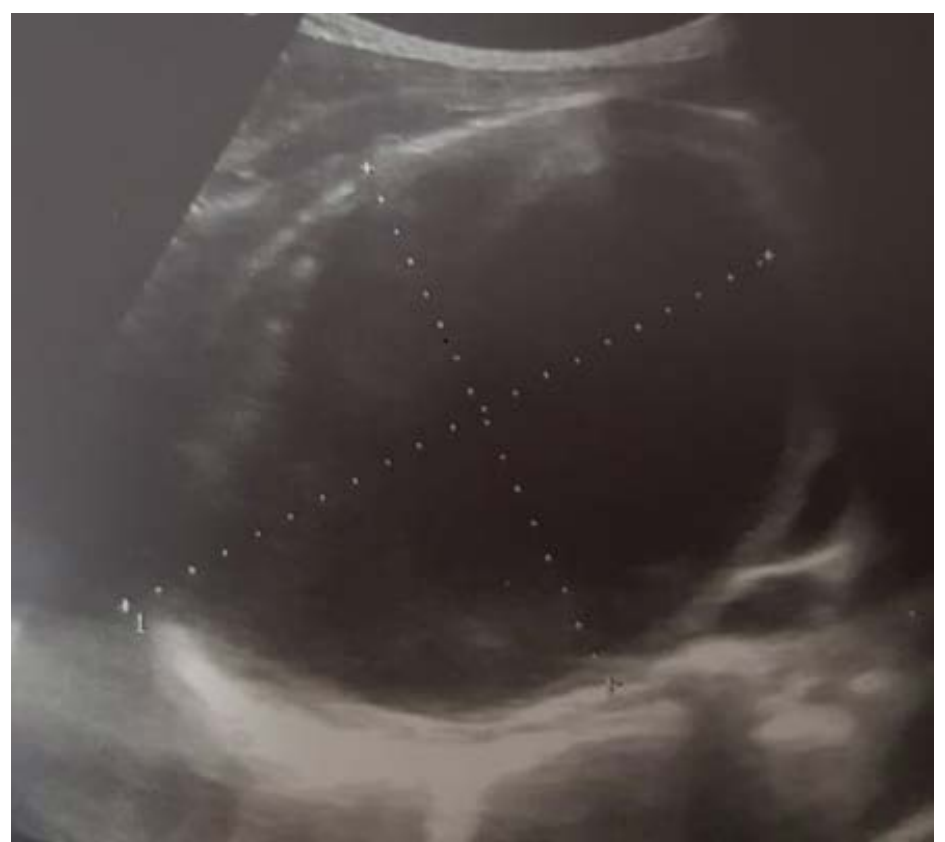

Figure 1. Intact right lung hydatid cyst measuring $12 \times 8 \mathrm{~cm}$.

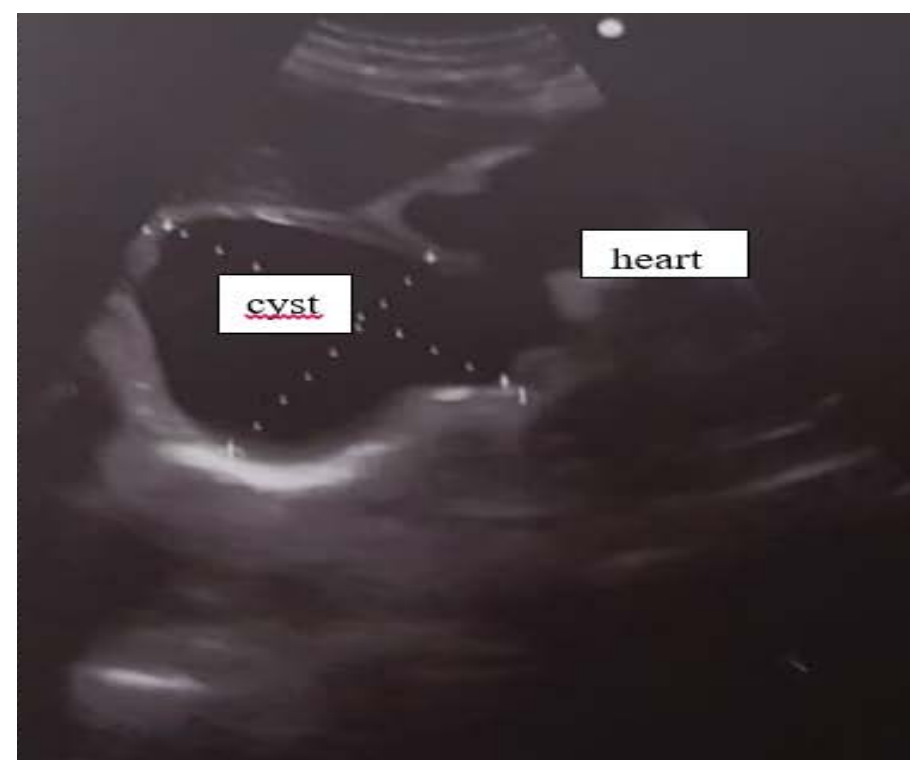

Figure 2. Intact right lung hydatid cyst attached to the heart measuring $11 \mathrm{x} 7 \mathrm{~cm}$. 


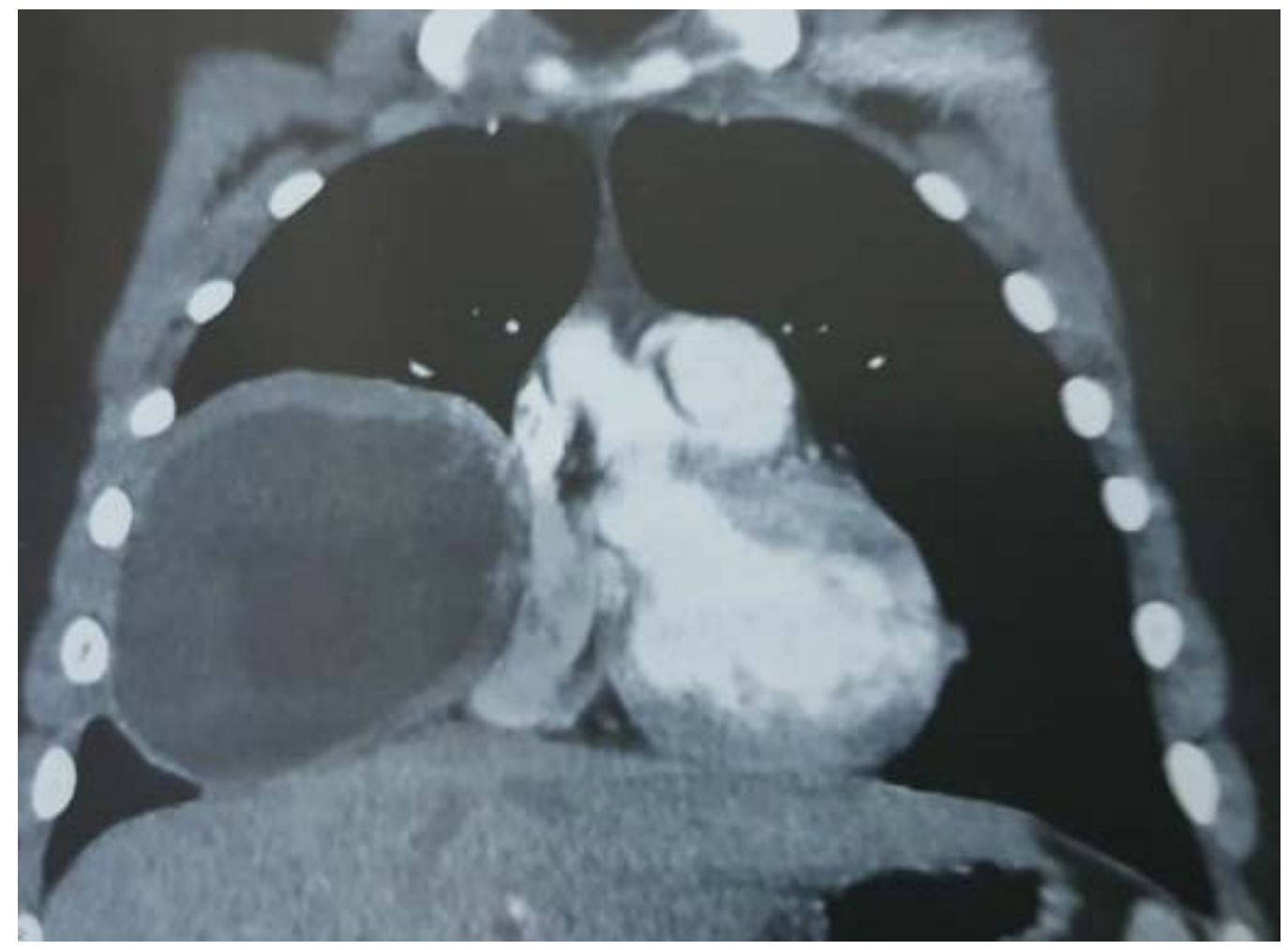

Figure 3. Intact giant hydatid cyst of the middle lobe compressing the right cardiac cavities measuring $87 \times 94 \times 75 \mathrm{~mm}$.

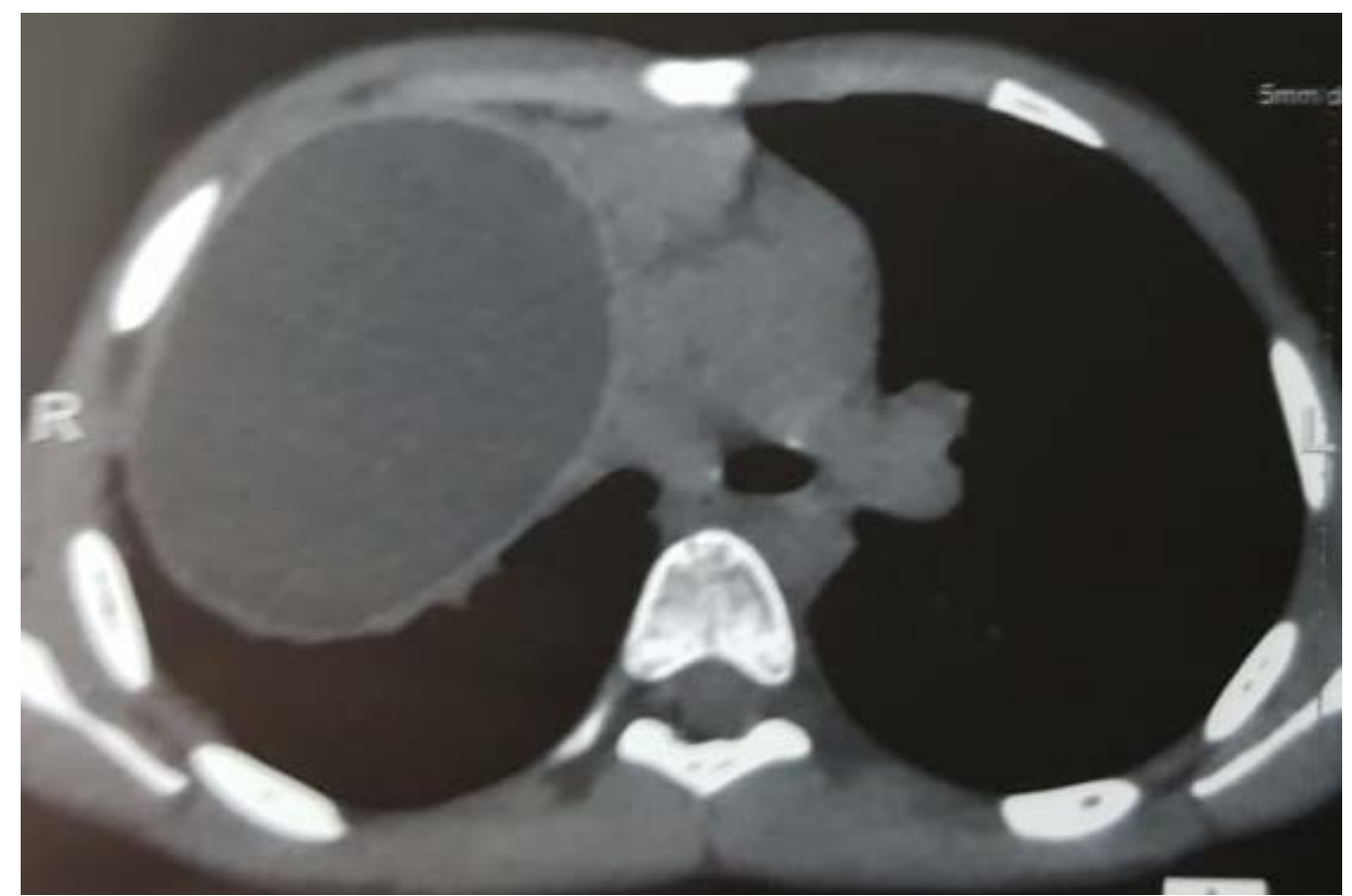

Figure 4. Mediastinopulmonar giant hydatid cyst repressing the right brachiocephalic vein, the superior vena cava and the right atrium. 
Table 2. Post-operative complications (intact vs complicated).

\begin{tabular}{|l|c|c|c|}
\hline & $\begin{array}{c}\text { Intact cysts } \\
(\mathrm{n}=62)\end{array}$ & $\begin{array}{c}\text { Complicated cysts } \\
(\mathrm{n}=43)\end{array}$ & $\mathrm{p}$ value \\
\hline Pneumonia & $5 \%$ & $5 \%$ & $>0.05$ \\
\hline $\begin{array}{l}\text { Prolonged air } \\
\text { drainage }\end{array}$ & $4 \%$ & $5 \%$ & $>0.05$ \\
\hline atelectasis & $2 \%$ & $5 \%$ & $>0.05$ \\
\hline
\end{tabular}

Table 3. Post-operative complications (giant vs other cysts).

\begin{tabular}{|c|c|c|c|}
\hline & $\begin{array}{c}\text { Giant cysts } \\
(\mathrm{n}=24)\end{array}$ & $\begin{array}{c}\text { Other cysts } \\
(\mathrm{n}=81)\end{array}$ & p value \\
\hline Pneumonia & $13 \%$ & $3 \%$ & 0.043 \\
\hline $\begin{array}{c}\text { Prolonged air } \\
\text { drainage }\end{array}$ & $12 \%$ & $7 \%$ & $>0.05$ \\
\hline Atelectasis & $8 \%$ & $1 \%$ & $>0.05$ \\
\hline
\end{tabular}




\section{Authorship and Contributorship}

\section{Authorship agreement}

I have made substantial contributions to the conception or design of the work (Giant pulmonary hydatid cyst in children); or the acquisition, analysis, or interpretation of data for the work; AND

I have drafted the work or revised it critically for important intellectual content; AND

I have approved the final version to be published; AND

I agree to be accountable for all aspects of the work in ensuring that questions related to the accuracy or integrity of any part of the work are appropriately investigated and resolved.

All persons who have made substantial contributions to the work reported in the manuscript, including those who provided editing and writing assistance but who are not authors, are named in the Acknowledgments section of the manuscript and have given their written permission to be named. If the manuscript does not include Acknowledgments, it is because the authors have not received substantial contributions from nonauthors.
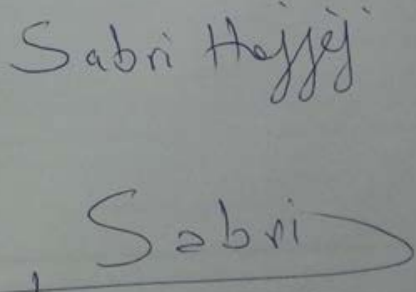


\section{Authorship agreement:}

I have made substantial contributions to the conception or design of the work (Giant pulmonary hydatid cyst in children); or the acquisition, analysis, or interpretation of data for the work; And I have drafted the work or revised it critically for important intellectual content: and

I have approved the final version to be published; and

1 agree to be accountable for all aspects of the work in ensuring that questions related to the accuracy or integrity of any part of the work are appropriately investigated and resolved.

All persons who have made substantial contributions to the work reported in the manuscript, including those who provided editing and writing assistance but who are not authors, are named in the Acknowledgments section of the manuscript and have given their written permission to be named. If the manuscript does not include Acknowledgments, it is because the authors have not received substantial contributions from non authors.

\section{Dr Safo Beklir}
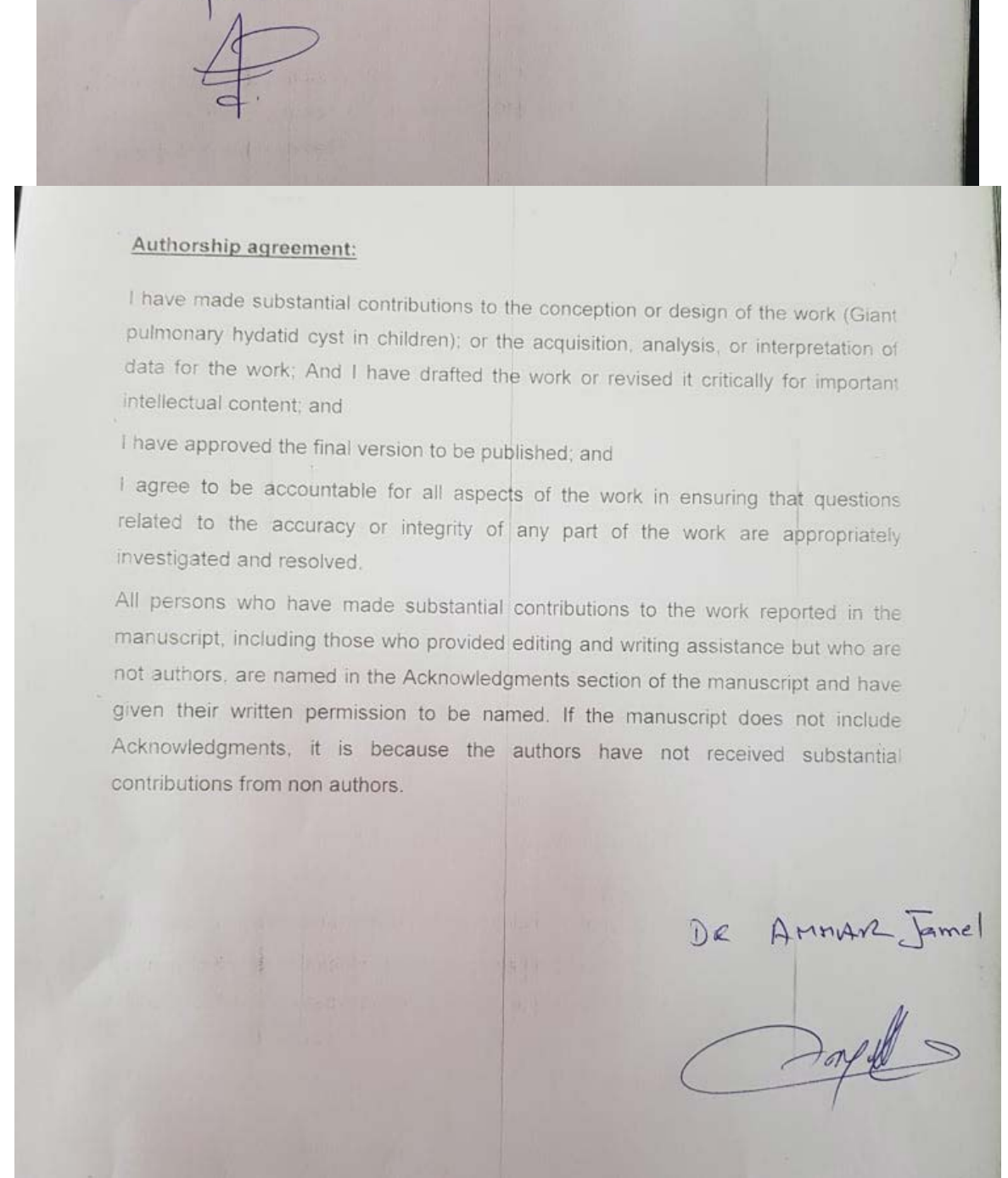


\section{Authorship agreement:}

I have made substantial contributions to the conception or design of the work (Giant pulmonary hydatid cyst in children); or the acquisition, analysis, or interpretation of data for the work; And I have drafted the work or revised it critically for important intellectual content; and

I have approved the final version to be published; and

I agree to be accountable for all aspects of the work in ensuring that questions related to the accuracy or integrity of any part of the work are appropriately investigated and resolved.

All persons who have made substantial contributions to the work reported in the manuscript, including those who provided editing and writing assistance but who are not authors, are named in the Acknowledgments section of the manuscript and have given their written permission to be named. If the manuscript does not include Acknowledgments, it is because the authors have not received substantia contributions from non authors.

$$
\text { It Agnes Hanzaar }
$$

\section{Authorship agreement:}

I have made substantial contributions to the conception or design of the work (Giant pulmonary hydatid cyst in children); or the acquisition, analysis or interpretation of data for the work; And I have drafted the work or revised it critically for importan intellectual content; and

I have approved the final version to be published; and

I agree to be accountable for all aspects of the work in ensuring that questions related to the accuracy or integrity of any part of the work are appropriately investigated and resolved.

All persons who have made substantial contributions to the work reported in the manuscript, including those who provided editing and writing assistance but who are not authors, are named in the Acknowledgments section of the manuscript and have given their written permission to be named. If the manuscript does not include Acknowledgments, it is because the authors have not received substantia contributions from non authors.

\section{Dr Khalfallah IKbel}

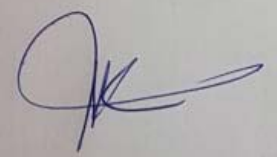




\section{Authorship agreement:}

I have made substantial contributions to the conception or design of the work (Giant pulmonary hydatid cyst in children); or the acquisition, analysis, or interpretation of data for the work; And I have drafted the work or revised it critically for importan intellectual content, and

I have approved the final version to be published; and

I agree to be accountable for all aspects of the work in ensuring that questions related to the accuracy or integrity of any part of the work are appropriately investigated and resolved.

All persons who have made substantial contributions to the work reported in the manuscript, including those who provided editing and writing assistance but who are 'not authors, are named in the Acknowledgments section of the manuscript and have given their written permission to be named. If the manuscript does not include Acknowledgments, it is because the authors have not received substantia contributions from non authors.
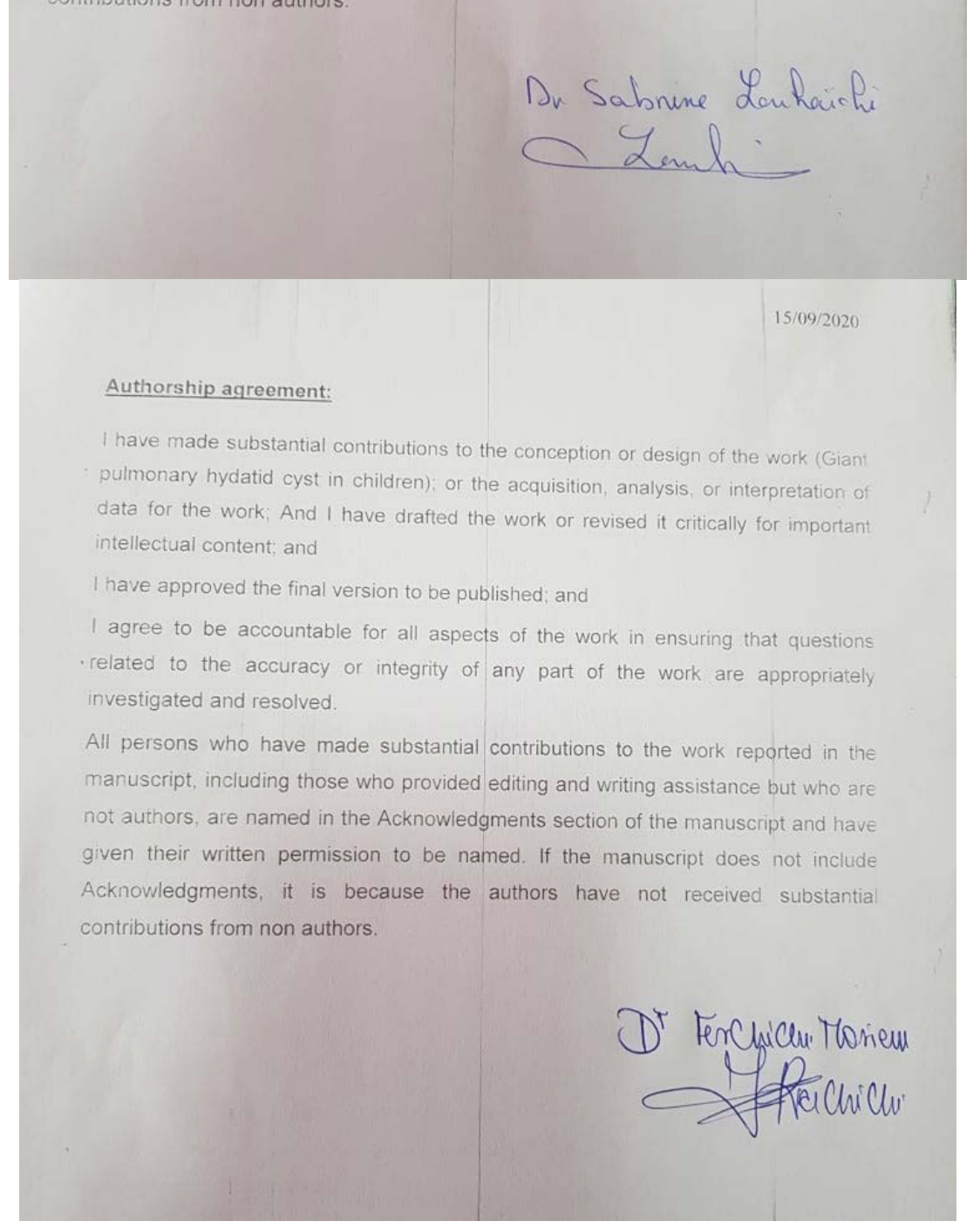


\section{Authorship agreement:}

I have made substantial contributions to the conception or design of the work (Giant pulmonary hydatid cyst in children); or the acquisition, analysis, or interpretation of data for the work: And I have drafted the work or revised it critically for importan intellectual content; and

I have approved the final version to be published; and

I agree to be accountable for all aspects of the work in ensuring that questions related to the accuracy or integrity of any part of the work are appropriately investigated and resolved.

All persons who have made substantial contributions to the work reported in the manuscript, including those who provided editing and writing assistance but who are not authors, are named in the Acknowledgments section of the manuscript and have given their written permission to be named. If the manuscript does not include Acknowledgments, it is because the authors have not received substantia contributions from non authors.

Dr Berma Hande 